\title{
Hip muscle and hand-grip strength to differentiate between older fallers and non-fallers: a cross- sectional validity study
}

This article was published in the following Dove Press journal:

Clinical Interventions in Aging

\author{
Simone C Gafner, ${ }^{1,2}$ \\ Caroline H Bastiaenen, ${ }^{2,3}$ \\ Serge Ferrari, ${ }^{4}$ Gabriel \\ Gold, ${ }^{5}$ Philippe Terrier, ${ }^{6,7}$ \\ Roger Hilfiker, ${ }^{8}$ Lara Allet ${ }^{1,9}$ \\ 'Department of Physiotherapy, \\ HES-SO University of Applied \\ Sciences and Arts of Western \\ Switzerland, Geneva, Switzerland; \\ ${ }^{2}$ Department of Epidemiology, \\ Research Program Functioning \\ and Rehabilitation, CAPHRI, \\ Maastricht University, Maastricht, \\ the Netherlands; ${ }^{3}$ Department of \\ Health, School of Health Professions, \\ Zurich University of Applied Sciences, \\ Winterthur, ${ }^{4}$ Department of Internal \\ Medicine Specialties, ${ }^{5}$ Department \\ of Internal Medicine, Rehabilitation \\ and Geriatrics, University Hospitals \\ and University of Geneva, Geneva, \\ ${ }^{6}$ Department of Research, Clinique \\ romande de réadaptation SUVACare, \\ ${ }^{7}$ Department of Research, Institute \\ for Research in Rehabilitation, Sion, \\ ${ }^{8}$ Department of Physiotherapy, School \\ of Health Sciences, HES-SO Valais- \\ Wallis, University of Applied Sciences \\ and Arts of Western Switzerland, \\ Valais, ${ }^{9}$ Department of Community \\ Medicine, University Hospitals \\ and University of Geneva, Geneva, \\ Switzerland
}

Correspondence: Simone C Gafner Department of Physiotherapy, HES-SO University of Applied Sciences and Arts of Western Switzerland, Rue des Caroubiers 25, CH 1227 Carouge,

Geneva, Switzerland

$\mathrm{Tel}+4$ I 223883470

Fax +4I 223883424

Email simone.gafner@hesge.ch
Background: Hip muscle weakness in older people seems to be an influencing factor of falls. Currently, it is unclear which muscles out of the hip muscle group play an important role in older people. A validating process in the measurement regarding muscle strength related to falls is necessary before answering that question.

Objective: Firstly, we aimed to investigate which hip muscle group strength shows an acceptable level of distinction between older adult fallers and non-fallers compared to a predefined external criterion regarding falling. Secondly, we aimed to compare the same outcomes and questions for hand-grip strength in relation to the same external criterion.

Design: This study was a cross-sectional validity study.

Methods: The maximum voluntary isometric strength (MVIS) and the rate of force generation of hip abductors (ABD), adductors, internal and external rotators, extensors, and flexors were measured with a dynamometer fixed to a custom-made frame as well as hand-grip strength with a Martin Vigorimeter in 60 older people aged over 65 years (38 females and 22 males).

Results: The area under the curve (AUC) and the results of the mean decrease in Gini index assessed by random forest approach show that of all the assessed parameters, hip ABD MVIS showed the highest discriminative value regarding the chosen external criterion in older people (AUC ABD MVIS 0.825, 95\% confidence interval: 0.712-0.938).

Conclusion: Results indicate that ABD MVIS is a useful measure to distinguish between older adult fallers and non-fallers regarding the chosen external criterion.

Keywords: hip muscle strength, accidental falls, older adults, hand-grip strength, measurement study

\section{Introduction}

High fall prevalence, especially multiple falls, increases the risk of independency loss, ${ }^{1}$ admission to nursing homes, ${ }^{2}$ reduction in quality of life, ${ }^{3}$ and mortality ${ }^{4}$ in older people. The World Health Organization (WHO) reports a worldwide fall rate of $\sim 28 \%-35 \%$ for people aged over 65 years. They also report a yearly fall rate of $\sim 30 \%-50 \%$ for people living in long-term care institutions, whereas $40 \%$ of these people show recurrent falls. ${ }^{5}$ The Federal Statistical Office (FSO), Switzerland, reports similar yearly fall rates of $25 \%$ for people over 65 years living at home ${ }^{6}$ and $39 \%$ for people in long-term care institutions. ${ }^{7}$

Lower limb weakness in older people is assumed to be an important influencing factor of falls ${ }^{8}$ and its preservation potentially contributes to the maintenance of independency. ${ }^{9}$ submit your manuscript Dovepress f cC. hereby accept the Terms. Non-commercial uses of the work are permitted without any further permission from Dove Medical Press Limited, provided the work is properly attributed. For permission for commercial use of this work, please see paragraphs 4.2 and 5 of our Terms (https://www.dovepress.com/terms.php). 
There are several reasons for the increasing interest in the relationship between hip muscle strength and fall risk of older people. Approximately $7 \%$ of older people suffer from peripheral neuropathy, ${ }^{10}$ which is a predominantly distal dysfunction linked to an increased fall risk. ${ }^{11}$ Preservation of proximal lower limb strength might enable older people to compensate for distal nerve function losses. ${ }^{12} \mathrm{Next}$, older people tend to show a more accentuated hip strategy, whereas younger counterparts use rather, an ankle strategy to keep their balance. ${ }^{13}$ Finally, older people, in particular fallers, have a reduced mediolateral stability while standing ${ }^{14}$ and increased mediolateral body motion during dynamic balance recovery in forward stepping tasks. ${ }^{15}$ This mediolateral control is mainly assured through proximal (hip) frontal plane muscle strength. Therefore, hip muscle strength might be an important parameter to include in fall-risk assessment and can have a role in the prevention and rehabilitation in an older population at risk of falls. Hip muscle strength is an easily assessable parameter, and most importantly, easy to target in physical therapy. To contribute to treatment goal setting, insight into the diagnostic accurary of hip muscle strength measurement to apply in an older population at risk of falling seems to be important.

To the best of our knowledge, no study exists that simultaneously assessed and compared all six hip muscle groups to investigate diagnostic values to discriminate between older adults with and without fall history (as an assumed external criterion). Fall history is known as a risk factor for future falls. ${ }^{16}$ However, its assessment does not give us a directly targetable parameter for physical therapy treatment.

In addition, a separate comparison between hip muscle strength and hand-grip strength with the same external criterion has not yet been investigated. At the moment, hand-grip strength is assumed to be a parameter related to whole body strength and fall risk. ${ }^{17}$

To validate the new measurement tool, the first step is to compare the currently used assessments with the new, to-be developed fall-risk assessment tool to get an idea about its discriminating ability between older adult fallers and nonfallers. Future studies will have to prospectively assess the strength of hip muscle groups with the highest diagnostic accuracy.

Our aims were as follows:

1) To identify the distinction level of the different hip muscle strength groups, evaluated by the area under the curve (AUC) $>0.7$, compared to a predefined external criterion regarding falling by measuring maximal voluntary isometric strength (MVIS) and rate of force generation (RFG).
2) To compare the outcomes of hip muscle strength with hand-grip strength compared to the same external criterion.

We hypothesized that, 1) within the group of hip muscles, the hip frontal plane muscle groups, essentially hip abductor (ABD) strengths, show the highest level of AUC $>0.7$, and 2) that the outcomes of frontal plane hip muscle strength expressed in AUC have higher values than hand-grip strength compared to the same external criterion.

\section{Methods}

We examined the concurrent validity of the strength of different hip muscle strength groups as well as hand-grip strength compared to older participants' history of falling as external criterion. The data collection was performed cross-sectionally. The study was designed according to the guidelines of the COSMIN taxonomy regarding criterion validity. ${ }^{18}$

\section{Participants}

In a limited period of time, from March to October 2015, sixty participants were simultaneously recruited from the Geriatric Department of the University Hospital of Geneva as well as from an ambulatory setting. The two different settings guaranteed the heterogeneous sample needed for a validity study. Participants admitted to physical therapy for musculoskeletal or vascular disorders were consecutively checked for the inclusion and exclusion criteria (see the following section), and thereafter asked if they agreed to participate in this study (Figure 1). The protocol was approved by the ethics committee of Geneva (Commission cantonale d'éthique de la recherche [CCER] 14-235). All participants received written and verbal information relating to the study and signed written informed consent was received from 67 participants.

Participants $>65$ years old, with a body mass index (BMI) between 17 and 35, and who were able to walk household distances were included in the study. They were excluded in the case of a positive history or evidence of any significant central nervous system dysfunction, neuromuscular disorders except a distal symmetric peripheral neuropathy, evidence of vestibular dysfunction, moderate or severe dementia (Mini Mental State Examination [MMSE] <18), a fracture of the lower limb and/or joint replacement within the previous year, and any lower limb or back pain that would adversely affect the strength tests.

\section{Measures}

\section{External criterion}

The external criterion was defined as a positive fall history within the previous 12 months. Participants reporting one or 


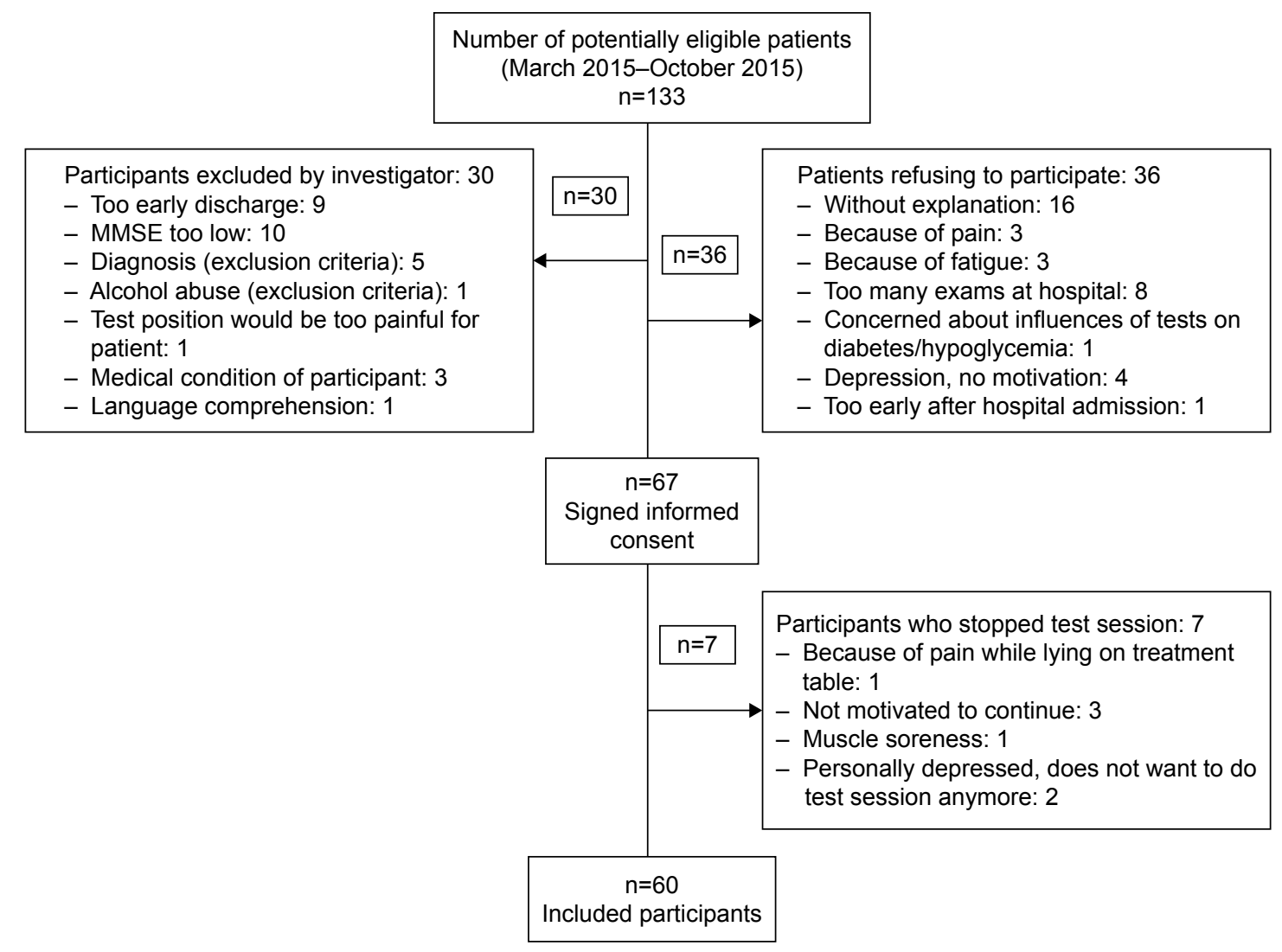

Figure I Flowchart that explains the recruitment process of the participants. Abbreviation: MMSE, Mini Mental State Examination.

more falls in the past year were classified as fallers. ${ }^{19}$ People that did not fall were classified as non-fallers. ${ }^{19}$ An event that results in a person coming to rest inadvertently on the ground or floor or other lower level was defined as a fall. ${ }^{5}$ The fall history was chosen as external criterion in this study because of the ultimate importance of this discriminating factor within our theoretical construct of contributing factors regarding fall risk in older people. Identifying a suitable criterion that is considered to represent the true state of the construct of interest is a challenge. As the construct of interest is discriminating older people in groups based on a directly targetable parameter related to a high risk of falling or not having a high risk of falling, fall history is a suitable external criterion.

\section{Index measures}

Hip strength was measured in Newton $(\mathrm{N})$ using an analog dynamometer (SENSIX ${ }^{\circledR}$; Sensix, Poitiers, France) with a measuring range from 0 to $667 \mathrm{~N}$ and a precision of $0.002 \mathrm{~N}$. The DELSYS System (Trigno Sensor; Delsys, Inc, Boston, MA, USA) coupled with the calibrated dynamometer digitalized the output $(3.3 \mathrm{~V})$ with a sampling rate of $1,926 \mathrm{~Hz}$ and a resolution of 16 bit. $^{20}$ To avoid bias induced by the testing people, the dynamometer was fixed to a frame for all strength tests. Hip MVIS (N/kg) and RFG (N/s/kg) were assessed in all anatomic planes. Subjects pushed as fast and as hard as possible against the dynamometer, ${ }^{21}$ held the pressure for three seconds, and then relaxed. ${ }^{12}$ Participants repeated all tests three times per leg with a break of 1 minute between each trial. The mean of the six trials was retained for further analyses. The starting position for each test was supported by the examiner in $1 \mathrm{~cm}$ distance of the dynamometer. The tester counted loudly from one to three to give the starting signal. Strong verbal encouragement was given during all measurements. The testing positions for the hip strength tests as well as the hand-grip strength are described in Table 1.

\section{Characteristics of the population}

The collected variables were age, gender, weight, BMI, the highest educational level achieved, ${ }^{27}$ reported dominant hand, the level of concern about falling assessed with the Falls Efficacy Scale International (FES-I) and cognitive impairments with the MMSE. 
Table I Hip strength test position, dynamometer placement, and hand-grip strength measurement position with Martin Vigorimeter

\begin{tabular}{|c|c|c|c|c|}
\hline $\begin{array}{l}\text { Strength } \\
\text { tests }\end{array}$ & Test position & $\begin{array}{l}\text { References } \\
\text { for test } \\
\text { positions }\end{array}$ & $\begin{array}{l}\text { Dynamometer } \\
\text { position }\end{array}$ & Special aspects to consider \\
\hline Hip flexors & $\begin{array}{l}\text { Supine with knee and hip in } 90^{\circ} \text { flexion } \\
\text { Neutral position according to rotations }\end{array}$ & $\begin{array}{l}\text { Mendis } \\
\text { et } \mathrm{al}^{22}\end{array}$ & $\begin{array}{l}5 \mathrm{~cm} \text { cranial to the } \\
\text { knee cap }\end{array}$ & $\begin{array}{l}\text { No special aspects to consider for this } \\
\text { testing position }\end{array}$ \\
\hline $\begin{array}{l}\text { Hip extensors } \\
(E X T)\end{array}$ & $\begin{array}{l}\text { Standing with the hip in neutral } \\
\text { position according to rotations }\end{array}$ & $\begin{array}{l}\text { Kollock } \\
\text { et } \mathrm{al}^{23}\end{array}$ & $\begin{array}{l}\text { In the middle of the line } \\
\text { between the os calcaneum } \\
\text { and the knee joint gap } \\
\text { on the posterior side } \\
\text { of the calf }\end{array}$ & $\begin{array}{l}\text { The knee had to stay extended and } \\
\text { the trunk in a neutral, upright position. } \\
\text { If participants could not perform the } \\
\text { test in the correct position, EXT was } \\
\text { reported as missing value }\end{array}$ \\
\hline $\begin{array}{l}\text { Hip internal } \\
\text { rotators }\end{array}$ & $\begin{array}{l}\text { Sitting position with the knee and hip } \\
\text { flexed at } 90^{\circ}\end{array}$ & $\begin{array}{l}\text { Thorborg } \\
\text { et } \mathrm{al}^{24}\end{array}$ & $\begin{array}{l}5 \mathrm{~cm} \text { cranial to the } \\
\text { external malleolus }\end{array}$ & $\begin{array}{l}\text { Special attention was paid so that } \\
\text { participants did not execute an } \\
\text { abduction movement of the hip }\end{array}$ \\
\hline $\begin{array}{l}\text { Hip external } \\
\text { rotators }\end{array}$ & $\begin{array}{l}\text { Sitting position with the knee and hip } \\
\text { flexed at } 90^{\circ}\end{array}$ & $\begin{array}{l}\text { Thorborg } \\
\text { et } \mathrm{al}^{24}\end{array}$ & $\begin{array}{l}5 \mathrm{~cm} \text { cranial to the } \\
\text { internal malleolus }\end{array}$ & $\begin{array}{l}\text { Special attention was paid so that } \\
\text { participants did not execute an } \\
\text { adduction movement of the hip }\end{array}$ \\
\hline Hip abductors & $\begin{array}{l}\text { Side-lying position with the upper leg } \\
\text { at } 10^{\circ} \text { abducted position. The lower } \\
\text { leg was in } 45^{\circ} \text { of knee and hip flexion } \\
\text { for stabilization }\end{array}$ & $\begin{array}{l}\text { Krause } \\
\text { et } \mathrm{al}^{25}\end{array}$ & $\begin{array}{l}5 \mathrm{~cm} \text { cranial to the } \\
\text { external malleolus }\end{array}$ & $\begin{array}{l}\text { The tested leg was extended, with the } \\
\text { hip in a neutral or slightly extended } \\
\text { position }\end{array}$ \\
\hline Hip adductors & $\begin{array}{l}\text { Side-lying position with the tested } \\
\text { lower leg in a neutral position. } \\
\text { The participant's upper leg was placed } \\
\text { on a pillow at } 90^{\circ} \text { hip and knee flexion }\end{array}$ & $\begin{array}{l}\text { Thorborg } \\
\text { et } \mathrm{al}^{24}\end{array}$ & $\begin{array}{l}5 \mathrm{~cm} \text { cranial to the medial } \\
\text { malleolus }\end{array}$ & $\begin{array}{l}\text { The tested leg was extended, with the } \\
\text { hip in a neutral or slightly extended } \\
\text { position }\end{array}$ \\
\hline $\begin{array}{l}\text { Hand-grip } \\
\text { strength }\end{array}$ & $\begin{array}{l}\text { Sitting on a chair with the elbow at } \\
90^{\circ} \text { flexion position. The forearm was } \\
\text { in a neutral position and the wrist at } \\
0^{\circ}-30^{\circ} \text { extension }\end{array}$ & $\begin{array}{l}\text { Desrosiers } \\
\text { et } \mathrm{al}^{26}\end{array}$ & $\begin{array}{l}\text { Participants were asked to } \\
\text { squeeze the rubber bulb } \\
\text { of the Martin Vigorimeter } \\
\text { as hard as possible and to } \\
\text { relax after three seconds }\end{array}$ & $\begin{array}{l}\text { No special aspects to consider for this } \\
\text { testing position }\end{array}$ \\
\hline
\end{tabular}

\section{FES-I}

Fear of falling is known to be an influencing factor of falls. ${ }^{28}$ FES-I is a validated questionnaire including 16 questions assessing the level of concern about falling of older people. ${ }^{29}$

\section{MMSE}

Cognitive impairment influences the fall risk in older adults. ${ }^{30}$ The MMSE is a widely used ${ }^{30}$ and validated assessment tool for cognitive impairments in older people consisting of 11 questions. $^{31}$

\section{Data collection}

After obtaining informed consent, we collected participants' sociodemographic data: age, gender, weight, and BMI - extracted from the clinical database - and the highest educational level achieved, dominant hand, and external criterion fall history via an interview. To further investigate the characteristics of our study population, a trained physical therapist assessed the MMSE and the FES-I. Then the subjects' hip strength and hand-grip strength were tested in the same way.

\section{Sample size}

We expected to find AUC values between good (0.8) and excellent (0.9). ${ }^{32}$ To test the null hypothesis $\mathrm{H}_{0}: \mathrm{AUC}=0.7$ $\left(\mathrm{H}_{1}: \mathrm{AUC} \neq 0.7\right)$ with an expected AUC of 0.85 , a sample of $n=48$ is appropriate to achieve a significance level of $5 \%$ and a power of $80 \% .^{33}$ In order to compensate for an expected drop-out rate of $20 \%$, we aimed to include a total of 60 participants.

\section{Statistical analyses}

Statistics were performed with Stata version 14.1 (Stata Corporation, College Station, TX, USA) and the statistical environment $R \cdot{ }^{34}$ Descriptive data (gender, age, weight, BMI, MMSE, FES-I) and the outcome data for strength are described in Tables 2 and 3. Missing data were not imputed in our statistics.

\section{Data processing}

The raw force signals were exported to Matlab (Mathworks, Natick, MA, USA; version 8.3.0.532). A low-pass filter (75 ms moving average) was applied to attenuate highfrequency noise. MVIS was defined as the peak value reached 
Table 2 Characteristics of our study participants

\begin{tabular}{llll}
\hline Variables & $\begin{array}{l}\text { All group; } \\
\text { mean (SD) }\end{array}$ & $\begin{array}{l}\text { Fallers; } \\
\text { mean (SD) }\end{array}$ & $\begin{array}{l}\text { Non-fallers; } \\
\text { mean (SD) }\end{array}$ \\
\hline Sex (F/M) & $38 / 22$ & $2 \mathrm{I} / \mathrm{II}$ & $\mathrm{I} / \mathrm{II}$ \\
Age (years) & $82.0(6.6)$ & $83.3(6.2)$ & $80.4(6.8)$ \\
Weight (kg) & $65.9(\mathrm{I} 2 . \mathrm{I})$ & $63.8(\mathrm{I} 2.7)$ & $68.3(\mathrm{II} .2)$ \\
BMI & $24.3(3.4)$ & $24.3(3.9)$ & $24.3(2.9)$ \\
MMSE & $26.0(3.5)$ & $24.3(3.6)$ & $27.8(2.1)$ \\
FES-I & $24.5(7.1)$ & $26.5(7.0)$ & $22.2(6.5)$ \\
\hline
\end{tabular}

Abbreviations: BMI, body mass index; MMSE, Mini Mental State Examination; FES-I, Falls Efficacy Scale International; F, female; M, male.

within 0 to 4 seconds. RFG was evaluated over $50 \mathrm{~ms}$ after $10 \%$ of the MVIS was reached. All hip strength values were normalized for participants' weight.

\section{Main analyses}

The diagnostic value of different hip muscle groups and hand-grip strength based on the gold standard (history taking of falling) was investigated with AUC of the receiver operating characteristics (Table 3) based on a univariable logistic regression. An AUC $>0.7$ is a moderately accurate level for a diagnostic test,${ }^{35}$ which we judged as an acceptable level for the clinical use of this diagnostic measurement tool. Participants with missing strength data were not included in the calculations of the AUC (see results).

The importance of the variables of the strength was investigated by random forest method with a consensus prediction reached for each observation by averaging the results of many

Table 3 Mean and standard deviation (SD) for hip muscle strength groups and hand-grip strength presented for all group, fallers, and non-fallers separately

\begin{tabular}{|c|c|c|c|}
\hline & $\begin{array}{l}\text { All group } \\
\mathrm{n}=60 \\
\text { Mean (SD) }\end{array}$ & $\begin{array}{l}\text { Fallers } \\
\mathrm{n}=32 \\
\text { Mean (SD) }\end{array}$ & $\begin{array}{l}\text { Non-fallers } \\
\mathrm{n}=\mathbf{2 8} \\
\text { Mean (SD) }\end{array}$ \\
\hline ABD MVIS (N/kg) & $\mathrm{I} .0(0.5)$ & $0.7(0.3)$ & I.2(0.5) \\
\hline ABD RFG (N/kg/s) & $6.3(4.5)$ & $4.2(2.7)$ & $8.8(5.0)$ \\
\hline ADD MVIS (N/kg) & I.I (0.5) & $0.9(0.4)$ & $1.3(0.4)$ \\
\hline ADD RFG (N/kg/s) & $4.4(3.1)$ & $3.3(2.3)$ & $5.7(3.4)$ \\
\hline ER MVIS (N/kg) & $0.8\left(0.3^{*}\right)$ & $0.7\left(0.2^{* *}\right)$ & $0.9(0.3)$ \\
\hline ER RFG (N/kg/s) & $3.7\left(2.1^{*}\right)$ & $3.2(1.9 * *)$ & $4.3(2.1)$ \\
\hline IR MVIS (N/kg) & $1.2\left(0.3^{*}\right)$ & $\mathrm{I} . \mathrm{I}\left(0.3^{* *}\right)$ & $1.2(0.4)$ \\
\hline IR RFG (N/kg/s) & $4.2\left(2.1^{*}\right)$ & $3.8\left(1.8^{* *}\right)$ & $4.7(2.4)$ \\
\hline EXT MVIS (N/kg) & $1.3\left(0.5^{* * *}\right)$ & $1.2\left(0.4^{* *}\right)$ & $1.4\left(0.6^{* * * *}\right)$ \\
\hline EXT RFG (N/kg/s) & $5.9\left(3.5^{* * *}\right)$ & $5.2\left(3.7^{* *}\right)$ & $6.7(3.1 * * * *)$ \\
\hline FLEX MVIS (N/kg) & $1.7(0.6)$ & $1.4(0.4)$ & $2.0(0.6)$ \\
\hline FLEX RFG (N/kg/s) & $9.9(5.4)$ & $8.2(4.9)$ & $11.9(5.5)$ \\
\hline Hand-grip strength $(\mathrm{kPa})$ & $52.8(24.8)$ & $47.1(21.0)$ & $59.4(27.4)$ \\
\hline
\end{tabular}

Note: ${ }^{n}=58, * *_{n}=30, * * * n=57, * * * * n=27$.

Abbreviations: MVIS, maximum voluntary isometric strength; RFG, rate of force generation; ABD, hip abductors; ADD, hip adductors; FLEX, hip flexors; EXT, hip extensors; ER, hip external rotators; IR, hip internal rotators; SD, standard deviation. individual recursive partitioning tree models. ${ }^{36} \mathrm{~A}$ training set was drawn from the original data using bootstrap with replacement, and a classification tree was built. This was repeated 50,000 times and the final classification is the one that appears the most. The mean decrease in Gini index (DGI), which indicates the quality of a split for every variable by means of the Gini index, was calculated with the package randomForest ${ }^{37}$ within the statistical environment $R .^{34}$

\section{Results}

Sixty participants with a mean age of 82.0 years and a standard deviation (SD) of 6.61 were finally included in this study (Figure 1). Due to missing data (extensors: $n=3$; internal rotator: $n=2$; external rotator: $n=2$ ) of a total of four participants, the analyses of the AUC and DGI were performed including 56 participants. Most of our participants were right handed $(n=53)$ and had a medium educational level (terminated apprenticeship) $(n=34)$. Twenty participants had a low- (mandatory school) and six a high-educational level (university degree). Thirty-two participants reported one or more falls within the past 12 months (12 participants fell once, seven had two falls, 13 fell three times and more in the previous year). Twenty-eight participants did not fall in the past year (Table 2). The mean and SD of hip strength and hand-grip strengths are presented in Table 2.

The only hip muscle strength test with an AUC $>0.7$ based on the external criterion was the ABD MVIS (0.825, 95\% confidence interval [95\% CI]: 0.721-0.938) (Table 4). The importance of the variables was assessed through random forest approach (Figure 2), which also showed that the ABD MVIS is the most important variable among the tested muscle

Table 4 Area under the curve (AUC) for the hip muscle strength groups and hand-grip strength $(n=56)$

\begin{tabular}{lll}
\hline Hip muscle group & AUC & $\mathbf{9 5 \%} \mathbf{C l}$ \\
\hline ABD MVIS & 0.825 & $0.712-0.938$ \\
ABD RFG & 0.787 & $0.667-0.906$ \\
ADD MVIS & 0.773 & $0.648-0.897$ \\
FLEX MVIS & 0.755 & $0.628-0.882$ \\
ER MVIS & 0.741 & $0.610-0.87$ I \\
ADD RFG & 0.706 & $0.568-0.844$ \\
FLEX RFG & 0.678 & $0.536-0.820$ \\
ER RFG & 0.651 & $0.506-0.797$ \\
Hand-grip strength & 0.649 & $0.497-0.802$ \\
IR RFG & 0.617 & $0.467-0.766$ \\
EXT RFG & 0.610 & $0.460-0.761$ \\
IR MVIS & 0.576 & $0.422-0.730$ \\
EXT MVIS & 0.558 & $0.404-0.712$ \\
\hline
\end{tabular}

Abbreviations: MVIS, maximum voluntary isometric strength; RFG, rate of force generation; $\mathrm{Cl}$, confidence interval; $\mathrm{ABD}$, hip abductors; $\mathrm{ADD}$, hip adductors; FLEX hip flexors; EXT, hip extensors; ER, hip external rotators; IR, hip internal rotators. 


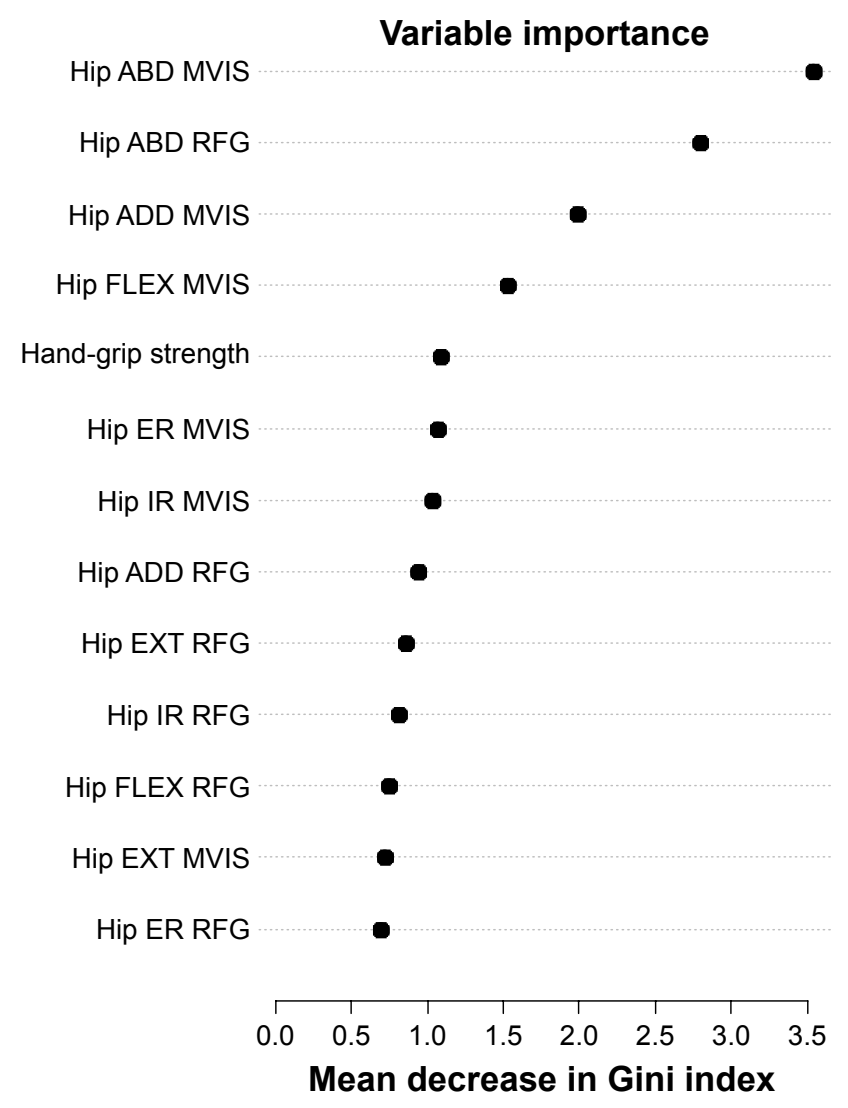

Figure 2 Mean decrease in Gini index sorted by decreasing variable importance from top to bottom. The two most important variables are the maximum voluntary isometric strength and rate of force generation of the hip abductors.

Abbreviations: MVIS, maximum voluntary isometric strength; RFG, rate of force generation; $A B D$, hip abductors; ADD, hip adductors; FLEX, hip flexors; EXT, hip extensors; IR, hip internal rotators; ER, hip external rotators.

groups. Hand-grip strength had an AUC of 0.649 (95\% CI: $0.497-0.802$ ) and stayed below the predefined AUC $>0.7$.

\section{Discussion}

Our results show that, 1) hip ABD MVIS has the best ability to distinguish between fallers and non-fallers (based on the fall history) and is the only muscle strength group (AUC of 0.825 ; 95\% CI: 0.721-0.938) with an AUC above the predefined level of 0.7 and, 2) hip frontal plane muscle strength (ABD and adductor [ADD]) distinguishes better than handgrip strength compared to the fall history (hand-grip strength AUC of 0.649 ; 95\% CI: $0.497-0.802$ ).

These results are an important first step to develop a new fall-risk assessment tool for older people. The fall risk of older people is influenced by multiple factors. ${ }^{38}$ Therefore, it is essential to know the importance of different contributing factors that shape a well-targeted treatment for the people at risk. Compared to the fall history, hip muscle strength deficits give information about a directly targetable fall-risk parameter, which contributes to treatment goal setting.
The increasing interest in hip muscle strength as a possible contributing factor to the fall risk of older people led to some studies in this field. ${ }^{9,21,39}$ However, none of them have given an indication on the muscle strength variable that influences the outcome parameter, falls, the most. The importance of the leading ABD variables as analyzed by DGI is followed by ADD MVIS, but the AUC, as well as ABD RFG, of this variable remains below 0.7 . This particularly supports our hypothesis of the importance of not only the ABD but also the whole frontal plane muscle strengths. The ADD RFG was ranked clearly lower in the DGI than ADD MVIS. The findings regarding the ABD RFG and ADD RFG seem surprising as a fast recovery step is necessary to regain balance after tripping. ${ }^{40}$ Therefore, one could assume that the RFG is more important to prevent a fall than the MVIS. The literature shows controversial findings regarding the importance of $\mathrm{RFG}^{19,40}$ and $\mathrm{MVIS}^{21}$ for the fall risk of older people. However, a recent article of Morcelli et $\mathrm{al}^{21}$ supports our findings, although they did not use the same strategy to analyze the data. Morcelli et $\mathrm{al}^{21}$ assessed hip ABD and ADD MVIS and RFG of older women classified as fallers and non-fallers according to their fall history of the previous 12 months. They identified significant differences between fallers and non-fallers regarding the late values of RFG of the ABD. Late values of RFG ( $\geq 90 \mathrm{~ms}$ after onset of contraction) are more related to MVIS than to the rate of force development. ${ }^{41}$

Our second hypothesis regarding diagnostic accuracy, comparison between the hip muscle strength and hand-grip strength with the same external criterion, was confirmed for $\mathrm{ABD}$ and ADD. Hand-grip strength is assumed to be less accurate for fall-risk assessment than lower limb strength as it is, for example, not directly linked to balance recovery. ${ }^{17}$ Our findings are supported by this study.

This project was the first to investigate the strength of all hip muscle groups in a population of older age to identify hip muscle groups above a predefined level of diagnostic accuracy for fall history, and consequently their clinical use. The reduction observed in the total test battery to only one parameter (hip ABD strength), measurable in a short time frame, is very important for this age group.

Therefore, this outcome is a perfect starting point. Future research should investigate the value of hip ABD strength for the assessment of the fall risk in older people. If hip ABD strength shows a clear association with falls, then a proper evaluation of hip strength deficits besides the assessment of other risk factors should be integrated in the commonly used assessments in order to enable clinicians to design bettertailored treatment programs. 
The method of measuring hip ABD, by a dynamometer fixed to a custom-made frame attached to a regular physical therapy treatment table, we chose in this study is practicable and feasible with older adults in everyday clinics. ${ }^{20}$ The time to install and measure participants' hip $\mathrm{ABD}$ is $10.58 \pm 1.56$ minutes. ${ }^{20}$ Further, our measurement method was proven in our earlier article to have a good reliability. ${ }^{20}$

Our investigation on the strength of hip muscle groups in hospitalized and outpatient settings allowed us to get detailed information on the full range of applicability of this new measurement tool. The reduced test battery, an easily practicable measurement method in daily clinics, and wide applicability range further facilitate the investigation and implementation of this easily targetable fallrisk parameter.

A point to consider in future investigations of $\mathrm{ABD}$ MVIS as a fall-risk assessment tool is the fall prevalence of the sample under study. Some of our participants were recruited in a geriatric hospital known for its fall-risk prevention interventions. This led to our higher fall prevalence (53\%); the worldwide fall rate of older people as reported by WHO is $28 \%-35 \%{ }^{5}$ This higher prevalence only slightly influences the results of the AUC and DGI but can possibly lead to a small overestimation of the diagnostic accuracy of a measurement instrument.

Our sample size was calculated prospectively to achieve a power of $80 \%$; nonetheless, sixty participants is a rather small sample size for this heterogeneous population. Therefore, to allow a wide clinical use, hip ABD MVIS should be further investigated in a broader setting of older people to gather insight into its diagnostic accuracy for daily clinical use as a fall-risk assessment tool. Lastly, we assessed our participants MVIS and RFG in the same trial and found only a slightly weaker ability to distinguish between fallers and non-fallers based on ABD RFG compared to the ABD MVIS. Due to the complexity of this task for older people, this combined measurement of MVIS and RFG could have influenced the study results and should be investigated in two different trials to allow a stricter differentiation of the results for MVIS and RFG.

\section{Conclusion}

Hip ABD seemed to be an important hip muscle group to distinguish between older adult fallers and non-fallers compared with the chosen external criterion, history of falling. In our population, hand-grip strength has a lower ability to distinguish between the two groups than $\mathrm{ABD}$ and $\mathrm{ADD}$.
Future studies should focus on the diagnostic accuracy of ABD MVIS and a specific hip ABD muscle training to decrease fall risk.

\section{Acknowledgments}

We kindly thank all our study participants for their participation as well as all physical therapists who assisted us during patient recruitment. The abstract of this paper was presented on October 19, 2017, as a poster presentation with interim findings at the "1st Cooperation congress of Reha Schweiz and Physioswiss" in Davos, Switzerland.

\section{Disclosure}

The authors report no conflicts of interest in this work.

\section{References}

1. Vermeulen J, Neyens JC, van Rossum E, Spreeuwenberg MD, de Witte LP Predicting ADL disability in community-dwelling elderly people using physical frailty indicators: a systematic review. BMC Geriatr. 2011;11:33

2. Tinetti ME, Williams CS. Falls, injuries due to falls, and the risk of admission to a nursing home. N Engl J Med. 1997;337(18):1279-1284.

3. Muller M, Maier AB, Smulders YM. [High blood pressure and mortality in the elderly: what does gait speed tell?]. Ned Tijdschr Geneeskund. 2013;157(7):A5801

4. Liu SW, Obermeyer Z, Chang Y, Shankar KN. Frequency of ED revisits and death among older adults after a fall. Am J Emerg Med. 2015;33(8):1012-1018.

5. WHO. World Health Organization Report/WHO Global Report on Falls Prevention in Older Age. Geneva: WHO; 2007.

6. Swiss Federal Statistical Office. Schweizerische Gesundheitsbefragung 2012; Die funktionale Gesundheit von älteren Menschen in Privathaushalten. Switzerland: Swiss Federal Statistical Office; 2014.

7. Swiss Federal Statistical Office. Gesundheit von Betagten in Altersund Pflegeheimen Erhebung zum Gesundheitszustand von betagten Personen in Institutionen (2008/2009). Switzerland: Swiss Federal Statistical Office; 2012.

8. Muir SW, Berg K, Chesworth BM, Klar N, Speechley M. Modifiable risk factors identify people who transition from non-fallers to fallers in community-dwelling older adults: a prospective study. Physiother Can. 2010;62(4):358-367.

9. Batista FS, Gomes GA, D'Elboux MJ, et al. Relationship between lower-limb muscle strength and functional independence among elderly people according to frailty criteria: a cross-sectional study. Sao Paulo Med J. 2014;132(5):282-289.

10. Hanewinckel R, van Oijen M, Ikram MA, van Doorn PA. The epidemiology and risk factors of chronic polyneuropathy. Eur J Epidemiol. 2016;31(1):5-20.

11. Hoffman EM, Staff NP, Robb JM, St Sauver JL, Dyck PJ, Klein CJ. Impairments and comorbidities of polyneuropathy revealed by population-based analyses. Neurology. 2015;84(16):1644-1651.

12. Allet L, Kim H, Ashton-Miller J, De Mott T, Richardson JK. Frontal plane hip and ankle sensorimotor function, not age, predicts unipedal stance time. Muscle Nerve. 2012;45(4):578-585.

13. Liaw MY, Chen CL, Pei YC, Leong CP, Lau YC. Comparison of the static and dynamic balance performance in young, middle-aged, and elderly healthy people. Chang Gung Med J. 2009;32(3):297-304.

14. Maki BE, Holliday PJ, Topper AK. A prospective study of postural balance and risk of falling in an ambulatory and independent elderly population. J Gerontol. 1994;49(2):M72-M84. 
15. Rogers MW, Hedman LD, Johnson ME, Cain TD, Hanke TA. Lateral stability during forward-induced stepping for dynamic balance recovery in young and older adults. J Gerontol A Biol Sci Med Sci. 2001;56(9): M589-M594.

16. Tinetti ME, Kumar C. The patient who falls: "It's always a trade-off". JAMA. 2010;303(3):258-266.

17. Pijnappels M, van der Burg PJ, Reeves ND, van Dieen JH. Identification of elderly fallers by muscle strength measures. Eur J Appl Physiol. 2008;102(5):585-592.

18. de Vet HCW, Terwee CB, Mokkink LB, Knol DL. Measurment in Medicine: A Practical Guide. Cambridge: Cambridge University Press; 2011.

19. Palmer TB, Thiele RM, Williams KB, et al. The identification of fall history using maximal and rapid isometric torque characteristics of the hip extensors in healthy, recreationally active elderly females: a preliminary investigation. Aging Clin Exp Res. 2015;27(4):431-438.

20. Gafner S, Bastiaenen CHG, Terrier P, et al. Evaluation of hip abductor and adductor strength in the elderly: a reliability study. Eur Rev Aging Phys Act. 2017;14:5.

21. Morcelli MH, Rossi DM, Karuka AH, et al. Peak torque, reaction time, and rate of torque development of hip abductors and adductors of older women. Physiotherapy Theory Pract. 2016;32(1):45-52.

22. Mendis MD, Wilson SJ, Hayes DA, Watts MC, Hides JA. Hip flexor muscle size, strength and recruitment pattern in patients with acetabular labral tears compared to healthy controls. Man Ther. 2014;19(5): 405-410.

23. Kollock RO Jr, Onate JA, Van Lunen B. The reliability of portable fixed dynamometry during hip and knee strength assessments. J Athl Train. 2010;45(4):349-356.

24. Thorborg K, Petersen J, Magnusson SP, Holmich P. Clinical assessment of hip strength using a hand-held dynamometer is reliable. Scand J Med Sci Sports. 2010;20(3):493-501.

25. Krause DA, Schlagel SJ, Stember BM, Zoetewey JE, Hollman JH. Influence of lever arm and stabilization on measures of hip abduction and adduction torque obtained by hand-held dynamometry. Arch Phys Med Rehabil. 2007;88(1):37-42.

26. Desrosiers J, Bravo G, Hebert R, Dutil E. Normative data for grip strength of elderly men and women. Am J Occup Ther. 1995;49(7):637-644.

27. Burgi F, Niederer I, Schindler C, et al. Effect of a lifestyle intervention on adiposity and fitness in socially disadvantaged subgroups of preschoolers: a cluster-randomized trial (Ballabeina). Prev Med. 2012; 54(5):335-340.
28. Young WR, Mark Williams A. How fear of falling can increase fall-risk in older adults: applying psychological theory to practical observations. Gait Posture. 2015;41(1):7-12.

29. Yardley L, Beyer N, Hauer K, Kempen G, Piot-Ziegler C, Todd C. Development and initial validation of the Falls Efficacy ScaleInternational (FES-I). Age Ageing. 2005;34(6):614-619.

30. Muir SW, Gopaul K, Montero Odasso MM. The role of cognitive impairment in fall risk among older adults: a systematic review and meta-analysis. Age Ageing. 2012;41(3):299-308.

31. Folstein MF, Folstein SE, McHugh PR. "Mini-mental state". A practical method for grading the cognitive state of patients for the clinician. J Psychiatr Res. 1975;12(3):189-198.

32. Youngstrom EA. A primer on receiver operating characteristic analysis and diagnostic efficiency statistics for pediatric psychology: we are ready to ROC. J Pediatr Psychol. 2014;39(2):204-221.

33. Hajian-Tilaki K. Sample size estimation in diagnostic test studies of biomedical informatics. J Biomed Inform. 2014;48:193-204.

34. R Core Team. R: A Language and Environment for Statistical Computing. Vienna, Austria: R Foundation for Statistical Computing; 2014.

35. Greiner M, Pfeiffer D, Smith RD. Principles and practical application of the receiver-operating characteristic analysis for diagnostic tests. Prev Vet Med. 2000;45(1-2):23-41.

36. Breiman L. Random forests. Machine Learning. 2001;45(1):5-32.

37. Liaw A, Wiener M. Classification and regression by randomForest. R News. 2002;2/3:18-22

38. Tromp AM, Pluijm SM, Smit JH, Deeg DJ, Bouter LM, Lips P. Fall-risk screening test: a prospective study on predictors for falls in communitydwelling elderly. J Clin Epidemiol. 2001;54(8):837-844.

39. Morcelli MH, Crozara LF, Rossi DM, et al. Hip muscles strength and activation in older fallers and non-fallers. Isokinet Exerc Sci. 2014; 22:191-196.

40. Bento PC, Pereira G, Ugrinowitsch C, Rodacki AL. Peak torque and rate of torque development in elderly with and without fall history. Clin Biomech. 2010;25(5):450-454.

41. Andersen LL, Aagaard P. Influence of maximal muscle strength and intrinsic muscle contractile properties on contractile rate of force development. Eur J Appl Physiol. 2006;96(1):46-52.
Clinical Interventions in Aging

\section{Publish your work in this journal}

Clinical Interventions in Aging is an international, peer-reviewed journal focusing on evidence-based reports on the value or lack thereof of treatments intended to prevent or delay the onset of maladaptive correlates of aging in human beings. This journal is indexed on PubMed Central, MedLine,

\section{Dovepress}

CAS, Scopus and the Elsevier Bibliographic databases. The manuscript management system is completely online and includes a very quick and fair peer-review system, which is all easy to use. Visit http://www.dovepress. com/testimonials.php to read real quotes from published authors. 